\title{
How SoTL-Active Faculty Members Can Be Cosmopolitan Assets to an Institution
}

\begin{abstract}
Faculty members engaged in the Scholarship of Teaching and Learning generate visible analyses of the learning taking place in their institutions, provide excellent models of practice for local colleagues, generate high-quality evidence for internal and external assessment, and offer accessible examples of quality education to prospective students. SoTL contributions of this kind should be nurtured by institutions as a basic expectation of high-quality instruction. I discuss these faculty contributions as assets derived from a cosmopolitan social role within their organizations, and I develop a recommendation for institutional strategy from that perspective.
\end{abstract}

\section{KEYWORDS}

cosmopolitan, institutional asset, assessment evidence, visible learning, public inquiry, reflective practice, effective instruction, institutional image

While being active in the Scholarship of Teaching and Learning (SoTL) has clear and significant benefits for the individuals participating, we should not underestimate or ignore the benefits of SoTL activity for the institutions in which those faculty members work. ${ }^{1}$ Rather than seeing SoTL work solely as a form of distinction that allows certain faculty members to rise in the hierarchy of scholars, a progressive institution will recognize SoTL as an important investment in the capacity of its community members. Given this analysis, it could be argued that treating teaching as a public inquiry into successful learning might be an essential feature of excellence in teaching, and an institution should make participation in SoTL part of its benchmark expectations for most of its teaching faculty members. First, I will identify a number of institutional advantages that accrue from having SoTL-active faculty members. Second, I will amplify the proposition by situating it in a model of social and organizational structure that identifies individuals who focus on internal (local) and external (cosmopolitan) frames of reference. Finally, I describe how this analysis can contribute to increased institutional recognition of SoTL activities.

\section{ANALYSIS OF ACADEMIC ASSETS}

In some ways, the contributions of SoTL work fit readily into a standard framework of assets. Faculty members who make their inquiry into teaching and learning visible to other scholars and to academic leaders from other institutions are productive in the con- 
ventional way. Their publications and presentations represent high quality work and ideas that are shared widely with colleagues. This form of scholarship has the properties of all public intellectual work: the products can be used directly, elaborated upon with further inquiry, and critiqued by peers on the quality of the evidence and analysis (Hutchings \& Shulman, 1999). These public traces of the work are also the foundation of the reputation of the institution the scholars work in. Academic standing for an institution is greatly enhanced when it has influential faculty members whose work is read and cited outside the home community.

There are also other ways that SoTL work is a tangible asset to an institution beyond the typical version of scholarly distribution. Since their teaching and their students' learning are typically well documented and often publicly visible, SoTL-active faculty members provide an accessible model of excellence in instructional design and reflective practice. It can be easier to create new variations of teaching if there are visible examples that demonstrate concretely what innovations look like and how they function. Perhaps on their own or in connection with a campus teaching center, these instructors present and discuss their work in local forums, often serving as facilitators of generative conversations among participating colleagues. An essential component of SoTL is reflection on the results of an inquiry, especially when that includes ideas and suggestions for the next steps in the evolution of the practices. As in any intellectual community, it is important to have examples of individuals who examine the results of their own work and describe how they will revise the next iteration to address the issues raised through their reflection.

All higher education institutions now undertake systematic description and examination of the quality of their students' intellectual products. Whether to suit internal decision making or under external constraint from governing boards or accreditation, the process of assessment is important public business for all institutions. Typical faculty members rarely volunteer to take on this important community activity, often pleading both lack of time in busy academic lives and lack of expertise in documenting learning for external audiences. It is challenging work to construct assignments that capture a deep understanding of the intellectual field being covered, and it takes practice to engage in reliable use of rubrics to place key components of student work along continua of development. For SoTL-active faculty members, however, every course offering is built upon serious consideration of the construction and evaluation of assignments. No new measures of learning need to be created, and the instructor has substantial experience with making judgments of quality in student thinking and writing. If most faculty members treat their teaching as a scholarly inquiry into learning, then assessment of programs and of the whole curriculum takes care of itself. The institution merely aggregates the work of those faculty members and offers an interpretative account of both progress and next steps for improvement. An additional bonus is that SoTL-active faculty members would already have experience writing just such accounts of the effectiveness of teaching.

During a period of declining public funding and stressed endowments, most institutions are challenged to discuss with students, parents, and the interested public how the persistently rising tuition revenue is being spent. Public relations staff are good at creating narrative accounts of the rationale for increases, and they also work hard to justify resources devoted to activities outside the teaching portion of each institution's mission. SoTL-active faculty members are already telling the story of teaching, often in the specific context of their home institution and its programs. When SoTL writing focuses on the 
performance of students, and on how that can be enhanced, it is a ready made blueprint for institutional written and multi-media presentations about the vitality of the teaching and learning environment on a campus. When faculty members are actively inquiring into best paths for increasing student success, the institution can demonstrate that it is focused on its primary audience. Instead of hunting around for faculty members who are willing to talk about how their research informs their teaching, institutions can highlight faculty members who are already going public to their professional peers about how they identify, implement, and evaluate the best ways to promote deep student learning. A smart institution will not only welcome this form of scholarship among its faculty members, but it will honor and grow their work as a major asset to the institution's public relations and fund raising functions.

An additional important asset of SoTL-active faculty members is their connection to the world of teaching beyond the boundaries of the campus, and often beyond the boundaries of their own field of study. Unlike discovery scholarship, which requires continuous contact with the work of scholars all over the globe, teaching in higher education has until recently been treated as largely a local enterprise. Until SoTL gradually emerged about 20 years ago, teaching in higher education was learned mostly from experience, on the receiving end as a student and then continuing with lessons learned on the job. In many cases, faculty members also learned by interacting with colleagues who passed on teaching tips or offered the opportunity to watch their work. Sometimes faculty members would attend teaching sessions included in or appended to their disciplinary conferences.

With the advent of SoTL conferences and publication outlets, faculty members have a rich new source of the latest and best-documented examples of innovative and effective instruction. They can bring to their department colleagues and to their entire institutions the benefits of work done in much broader arena. Instead of being deeply connected to research while remaining relatively provincial about teaching and learning, institutions can take full advantage of SoTL-active faculty members to keep the campus up-to-date on the best and most useful innovations in whole of higher education. This information has always been available, especially through the research and theoretical literature in education, but few faculty members have the time to read and decode research findings in another specialty. The SoTL world has opened up a flourishing and accessible source of work on teaching in specific contexts, and those faculty active in this domain are hugely valuable to their campuses.

\section{INTERNAL AND EXTERNAL PERSPECTIVE ON WORK}

Being a local point of access to the vast network of ongoing inquiry into teaching and learning is an especially good example of a distinction drawn by researchers in social structure and dynamics. Merton's (1957) analysis of interpersonal influence patterns in communities distinguished between people whose identity is connected with external values, events, and information (cosmopolitans) and people whose identity is oriented more to the values, concerns, and people in their own community (locals). Gouldner (1957) adapted Merton's ideas and labels in an analysis of professors, suggesting that more cosmopolitan faculty members connect their work outside their organization and more local faculty members orient their work on activities and issues within their organization. In particular, cosmopolitan community members are more likely to acknowledge a formal body of expertise in their work and more likely to make reference to an external 
community when evaluating quality and seeking innovation in ideas and practices. Merton's constructs and Gouldner's application of them to professional communities have been widely cited in analyses of professional commitment and identity (e.g., Blau, 1985; Kristof, 1996; Reichers, 1985). In an important way, SoTL-active faculty members are more likely to function as cosmopolitan community members than are their colleagues whose teaching is simply delivered in a professionally competent but conventional manner.

In order for faculty members to make their teaching work public, they need to know the venues for presenting inquiry into teaching and learning and the conventions for participation in them. Since most such venues include peer review of the quality of the work, faculty members need to read widely and use what they learn to develop and evaluate their own projects and practices. When sharing their teaching work with local colleagues, faculty members can do a great service to a community by serving as an efficient conduit to the best practices, innovations, ideas, and resources outside the immediate campus. Those innovations also include new ideas and models for assessment of student learning, many of which focus on meaningful performances and efficient ways to inform practice through evidence. A cosmopolitan faculty member can bring such practices to the attention of both colleagues and academic leaders so that assessment will be intrinsically useful to improving teaching and learning without being an unwelcome burden. Most higher education institutions' public presence highlights those ways in which its students, faculty, and staff are known and honored away from campus for their achievements. There may be no better way to attract enrollment than to highlight how many cosmopolitan faculty members are active and honored in SoTL communities around the nation and the world for their success in enhancing learning.

In essence, becoming cosmopolitan as a teacher has most of the same characteristics as becoming successful as a researcher (c.f., Glassick, Huber, \& Maeroff, 1997). In contemporary academics, only rarely is top-quality innovative work done in local isolation from the activities of others working in the same field. Just as we welcome and honor all faculty members who are cosmopolitan in their discovery scholarship, institutions can promote the careers of faculty members who are truly cosmopolitan in the teaching portion of their work. Participating in external intellectual communities is very valuable for both the individual and the institution, and it is essential to take full advantage of those intellectual assets to enrich the entire community's discourse on education and reputation for providing the best possible experiences and preparation for students.

\section{MANAGING ASSETS FOR CHANGE IN COMMUNITY VALUES AND PRACTICES}

Arguing for change in higher education policy is relatively easy in comparison with identifying strategies for change in the values and practices that drive those policies. Why is it that faculty members in general have not embraced the SoTL vision of public inquiry into student learning as an honored and viable professional path? Integrating a wide range of psychological and economic research, Tagg (2012) argued that faculty members are neither particularly resistant to change nor afraid of it. Instead, he suggested that we faculty members already hold a very desirable professional position, and like most people we favor decisions that avoid potential loss of current assets. There is plenty of recognition available for investing in individual discovery scholarship, including tenure and promo- 
tion. Tagg argued that reallocating time to scholarly inquiry into learning currently has a lower perceived probability of maintaining that recognition (in its many forms).

Tagg (2012) ends his analysis with suggestions that would promote change by enhancing the recognition and rewards associated with scholarly teaching, without presuming that fear or stubborn resistance are the real barriers to faculty change. As adapted to the framework of cosmopolitan teaching, three of his suggestions are relevant: (a) stop the exclusive linking of hiring, promotion, and tenure to disciplinary research, and include cosmopolitan work on teaching, (b) create faculty recognition for collaborative work that is visible for review, and (c) establish channels for building rewards outside of academic departments to encourage cosmopolitan work on teaching that benefits the institution. Making these changes will require both encouragement from academic leaders and leadership from tenured faculty members who stand up for the value of cosmopolitan, externally visible, and peer reviewed work on teaching. With SoTL-active faculty members, that kind of evidence will be available.

There is another area in which academic leaders and colleagues can play an important role in recognizing SoTL-active faculty members. In both Merton's (1957) and Gouldner's (1957) research on communities, there was an additional feature of cosmopolitan people that is worth considering: diminished loyalty to local institutions and activities. Community and faculty members identified as more cosmopolitan were less likely to devote time and energy to local initiatives that are of value mostly within the community or organization, and they are also more likely to seek and accept employment elsewhere. We already actively seek to retain the most cosmopolitan discovery scholars by arranging special working conditions, by rapid promotion to top ranks, and with superior compensation. In order to protect its teaching and learning assets, an institution needs to recognize those SoTL-active faculty members who would be of great value to any campus and proactively retain them in the usual manner. There will always be faculty members who identify or are recruited by a campus that offers colleagues or context that are too appealing to ignore. In most cases, however, an institution can avoid the downside of a cosmopolitan teaching career by building into its personnel system the usual recognitions for intellectual excellence, regardless of the particular domain of scholarship.

\section{RECOGNIZE, DEVELOP, AND PRESERVE INTELLECTUAL ASSETS THROUGH SOTL}

In summary, the best features of a SoTL-active faculty member's career are a huge asset to any institution, regardless of its place in the range of institutional missions. Academic leaders can and should take full advantage of the skills, knowledge, and visibility of their SoTL-active faculty colleagues to enhance both local function and the public standing of their institutions. It is not a complicated matter to do so, as we already recognize the value of cosmopolitan colleagues, and we need to do this while also sustaining the important work done by colleagues with a more local focus. SoTL should not be just a luxury for a few teaching leaders on a campus; rather it should be seen as an essential and continuous investment in the human capital of every institution.

Daniel Bernstein is a Professor of Psychology and the Director of the Center for Teaching Excellence at the University of Kansas. 


\section{NOTE}

1. Portions of this essay are derived from presentations at the National University of Singapore (October, 2010) and the International Society for the Scholarship of Teaching (October, 2011). I am grateful to two anonymous reviewers for helpful suggestions that enhanced the analysis.

\section{REFERENCES}

Blau, G.J. (1985). The measurement and prediction of career commitment. Journal of Occupational Psychology, 58, 277-288.

Gouldner, A.W. (1957). Cosmopolitans and locals: Toward an analysis of latent social rolesI. Administrative Science Quarterly, 2 (3), 281-306.

Glassick, C.E., Huber, M.T., \& Maeroff, G.I. (1997). Scholarship assessed: Evaluation of the professoriate. Hoboken, NJ: Jossey-Bass.

Hutchings, P., \& Shulman, L. (1999). The scholarship of teaching: New elaborations, new developments. Change, 31(5), 11-15.

Kristof, A.L. (1996). Person-organization fit: An integrative review of its conceptualization, measurement, and implications. Personnel Psychology, 49, 1-49.

Merton, R.K. (1957). Social theory and social structure. New York: Free Press.

Reichers, A.E. (1985). A review and reconceptualization of organizational commitment. The Academy of Management Review, 10 (3), 465-476.

Tagg, J. (2012). Why does the faculty resist change? Change, 44 (1), 6-15. 